African Journal of Pharmacy and Pharmacology Vol. 6(42), pp. 2905-2911, 15 November, 2012

Available online at http://www.academicjournals.org/AJPP

DOI: $10.5897 / A J P P 12.002$

ISSN 1996-0816 @ 2012 Academic Journals

\title{
Hepatoprotective and antioxidant activity of Spilanthes paniculata flower extracts on liver damage induced by paracetamol in rats
}

\author{
Syed Ayaz Ali" ${ }^{1 *}$, Shukla Mahanand ${ }^{1}$, Subur W. Khan ${ }^{2}$ \\ ${ }^{1}$ Department of Pharmacology, Y. B. Chavan College of Pharmacy, Dr. Rafiq Zakaria Campus, Rauza Bagh, \\ Aurangabad, Maharashtra, India \\ ${ }^{2}$ Department of Pharmacognosy, Y. B. Chavan College of Pharmacy, Dr. Rafiq Zakaria Campus, Rauza Bagh, \\ Aurangabad, Maharashtra, India.
}

Accepted 13 August, 2012

\begin{abstract}
The present study was undertaken to investigate the antioxidant and hepatoprotective effect of Spilanthes paniculata Wall. ex DC flower extracts against paracetamol-induced liver damage. The study was conducted in $\mathbf{3 6}$ male Wistar rats of either sex, and six groups were established. While the first group was maintained as normal control (NC, distilled water), Groups 2 to 6 were administered $3 \mathrm{~g} / \mathrm{kg}$ Paracetamol (PAR) for 2 day, $100 \mathrm{mg} / \mathrm{kg}$ Silymarin (SMR), $500 \mathrm{mg} / \mathrm{kg}$ Methanolic extract (MESP), Petroleum ether extract (PEESP), Ethyl acetate extract of $S$. paniculata (EAESP) suspended in $0.5 \%$ tween 80 plus PAR, respectively. PAR was administered in the same schedule as in group 2, the treatment with silymarin and extracts was given for 10 days orally, respectively. It was observed that PAR significantly increased serum Alanine transaminase (ALT), Aspartate transaminase (AST), Alkaline phosphatase (ALP) activity liver MDA levels $(P<0.01)$ and significantly decreased liver Glutathione (GSH), catalase (CAT), superoxide dismutase (SOD) activity $(P<0.01)$, when compared with the normal control group (NC). On the other hand, statistically significant $(P<0.01)$ changes were observed in the biochemical parameters of the group which was administered SMR, PEESP and EAESP. Compared with the pathological changes observed in the liver in the form of congested sinusoids and centrilobular necrosis, in the group which was administered paracetamol alone (PAR), lesions were determined to be less severe particularly in the group (PEESP and EAESP). The study shows that administration of PEESP and EAESP offered a therapeutic potential for the treatment of hepatotoxicity induced by paracetamol via regulation of endogenous antioxidant system in liver.
\end{abstract}

Key words: Spilanthes paniculata, paracetamol, biochemical parameters, oxidative stress, rats.

\section{INTRODUCTION}

Liver diseases have become one of the major causes of morbidity and mortality all over world. Among them, drug induced liver injury (DILI) is one of the most common causative factor that poses a major clinical and regulatory

${ }^{*}$ Corresponding author. E-mail: ayazpharm@gmail.com. Tel: +919960883737. Fax: 0240-2381129. challenge (Russmann et al., 2009). The manifestations of drug-induced hepatotoxicity are highly variable, ranging from asymptomatic elevation of liver enzymes to fulminant hepatic failure. Paracetamol (PAR) also known as Acetaminophen, taken in overdose can cause severe hepatotoxicity and nephrotoxicity (Vermeulen et al., 1991). PAR is activated and converted by cytochrome P450 enzymes to toxic metabolite N-acetyl-pbenzoquinoneimine (NAPQI) that causes oxidative stress 
and glutathione (GSH) depletion (Vermeulen et al., 1991; Cohen and Khairallah, 1997). In spite of tremendous advances in modem medicine, there are hardly any reliable drugs that protect the liver from damage and/or help in regeneration of hepatic cell. Many active plant extracts are frequently utilized to treat a wide variety of clinical diseases including liver disease (Chattopadhyay, 2003). Therefore, searching for effective and safe drugs for liver disorders is still considered as an area of interest.

Spilanthes paniculata Wall. ex DC, belongs to family Asteraceae is commonly known as toothache plant. It exhibits analgesic, strong larvicidal activity on Anopheles stephensi Liston, Anopheles culicifacies, antimicrobial and cytotoxic activity (Pandey and Agrawal, 2007). The plant is also used in the traditional system of medicine for the treatment of various disease complications including toothache, infections of throat and gums, paralysis of tongue, a popular remedy for stammering in children and as diuretic (The wealth of India, 2004).

Various pharmacological experimental studies have been carried out with $S$. acmmella another species of same genus. The chloroform, ethyl acetate, and methanol extracts, prepared from the aerial part of $S$. acmmella shows vasorelaxant and antioxidant activities (Wongsawatkul, 2008). Previous study has reported the presence of Stigmasterol, Sitosterol-o- $\beta$-D-glucoside in $S$. paniculata plant (Dinda and Guha, 1988). Our phytochemical investigation has revealed the presence of flavonoids, tannins, phenolic compounds and steroids in methanolic, petroleum ether, ethyl acetate extracts of $S$. paniculata flowers. Tannins, phenolic compounds were found to be absent in aqueous extract.

Taking into consideration the antioxidant potential of flavonoids and phenolic compounds present in the flower extracts the present study was conducted to evaluate the hepatoprotective and antioxidant potential of $S$. paniculata another species of the same genus spilanthes, plant extracts against paracetamol-induced hepatotoxicity in rats.

\section{MATERIALS AND METHODS}

\section{Drugs and chemicals}

Bovin serum albumin, Folin's ciocalteau phenol reagent, Pyrogallol, Thiobarbituric acid (TBA), 5'-dithiobis 2-nitrobenzoic acid (DTNB), Tris buffer, was procured from Hi-Media, Bombay, India. Paracetamol drug (Ipca Pvt. Ltd.) purchased from local medical store. All reagents procured and used were of analytical grade.

\section{Plant material}

The fresh flowers of $S$. paniculata plant were collected from Mazalgaon, district Beed (Maharashtra). The plant was identified, confirmed and authenticated by Department of Botany, Dr. Babasaheb Ambedkar Marathwada University, Aurangabad, Maharashtra State, India where voucher specimens have been deposited and accession is no.0730. The flowers were air dried indoors under subdued light with good ventilation and powdered with the help of grinder and stored in an airtight container. A methanolic extract was prepared by Soxhlet extraction method. The dried powdered flowers of $S$. paniculata were extracted with methanol for $36 \mathrm{~h}$ using Soxhlet extractor. The combined extracts were concentrated at $60^{\circ} \mathrm{C}$ under reduced pressure, to obtain dark brownish residue the remaining extract was freeze-dried.

The yield obtained from the foregoing process was found to be $2.53 \% \mathrm{w} / \mathrm{w}$. The extracts were preserved in a refrigerator for further use. The marc obtained from methanolic extract was dried and used further, similarly for the petroleum ether extraction for $36 \mathrm{~h}$. The yield obtained from the petroleum ether extraction process was found to be $2.76 \% \mathrm{w} / \mathrm{w}$. The marc obtained from petroleum ether extract was dried and used further, similarly for the ethyl acetate extraction was carried out for $36 \mathrm{~h}$. The yield obtained from the ethyl acetate process was found to be $2.60 \% \mathrm{w} / \mathrm{w}$.

\section{Phytochemical screening of S. paniculata flowers}

The Methanolic, Petroleum ether and Ethyl acetate extracts of $S$. paniculata flowers has shown presence of flavonoids, tannins phenolic compounds and steroids. The aqueous extract of $S$. paniculata flowers has shown presence of flavonoids and steroids but tannins, phenolic compounds were found to be absent.

\section{Animals}

Male Wistar rats weighing $150 \pm 15 \mathrm{~g}$ were used for this study. The animals were kept in polypropylene cages and maintained at $25 \pm$ $5^{\circ} \mathrm{C}$ under $12 \mathrm{~h}$ light/dark cycle. The animals were allowed free access standard pellet diet (Amrut Laboratory Rat feed, Navmaharashtra Chakan Oil Mills Ltd., Pune, India) and water ad libitum. The animal experiment was approved by Institutional Animal Ethics Committee of Y.B.Chavan College of Pharmacy, Aurangabad, Maharashtra and performed according to the guidelines laid by Institutional Animal Ethical Committee (IAEC) and Committee for the Purpose of Control and Supervision of Experiments on Animals (CPCSEA), Government of India.

\section{Study design}

Animals were divided into six groups of six rats each and treated orally as shown subsequently for 10 days. Group normal control (NC and received $0.5 \%$ tween 80 suspended in distilled water, 2.5 $\mathrm{ml} / \mathrm{kg}$ via gavage directly into the stomach), group PAR: animals were administered a single dose of $3 \mathrm{~g} / \mathrm{kg}$ PAR via gavage directly into the stomach, group SMR: animals were administered 100 $\mathrm{mg} / \mathrm{kg} /$ day Silymarin for 10 days plus $3 \mathrm{~g} / \mathrm{kg}$ PAR for 2 day, via gavage directly into the stomach, group MESP: animals were administered $500 \mathrm{mg} / \mathrm{kg} /$ day Methanolic extract of $S$. paniculata flowers (MESP) suspended in $0.5 \%$ tween 80 for 10 days plus 3 $\mathrm{g} / \mathrm{kg}$ PAR for 2 day, via gavage directly into the stomach, group PEESP: animals were administered $500 \mathrm{mg} / \mathrm{kg} /$ day Petroleum ether extract of $S$. paniculata flowers (PEESP) suspended in $0.5 \%$ tween 80 for 10 days plus $3 \mathrm{~g} / \mathrm{kg}$ PAR for 2 day, via gavage directly into the stomach, group EAESP: animals were administered 500 $\mathrm{mg} / \mathrm{kg} /$ day. Ethyl acetate extract of $S$. paniculata flowers (EAESP) suspended in $0.5 \%$ tween 80 for 10 days plus $3 \mathrm{~g} / \mathrm{kg}$ PAR for 2 day, via gavage directly into the stomach.

The rats included in the groups that were given paracetamol, silymarin and three extracts of $S$. paniculata (Groups 2 to 6) were weighed daily and accordingly dosed on body weight basis for 
Table 1. Effect of Silymarin and S. paniculata extracts on serum ALT, AST and ALP activities.

\begin{tabular}{lccc}
\hline Group & ALT (U/L) & AST (U/L) & ALP (U/L) \\
\hline NC & $40.76 \pm 3.44^{\dagger}$ & $143.22 \pm 8.20$ & $195.08 \pm 5.53$ \\
PAR & $144.88 \pm 8.14^{* \star \dagger}$ & $61.32 \pm 10.52^{* \star \dagger}$ & $513.36 \pm 9.17^{* *}+\dagger$ \\
SMR & $56.55 \pm 5.25^{\star *}$ & $154.56 \pm 3.02^{* *}$ & $199.98 \pm 3.59^{\star *}$ \\
MESP & $137.02 \pm 4.99^{\# \dagger \dagger}$ & $339.10 \pm 5.58^{\# \dagger \dagger}$ & $490.60 \pm 7.82^{\#+\dagger}$ \\
PEESP & $62.62 \pm 3.83^{* *}$ & $211.86 \pm 9.62^{* *} \dagger$ & $269.98 \pm 4.87^{* \star}$ \\
EAESP & $60.76 \pm 6.65^{* *}$ & $168.24 \pm 9.94^{* *}$ & $210.96 \pm 9.18^{* *}$ \\
\hline
\end{tabular}

Values are expressed as mean \pm S.E.M for six rats in each group. Comparisons were made with toxic group (PAR) vs. all treated groups and control group, ** represents statistical significance at $\mathrm{P}<0.01$ and ${ }^{\#}$ indicates non significance. ${ }^{\dagger}$ represents comparison made with group (SMR) vs. all treated groups, ${ }^{\dagger \dagger}$ represents statistical significance at $\mathrm{P}<0.01$ and $\dagger$ represents statistical significance at $\mathrm{P}<0.05$.

assuring more accuracy and safety.

\section{Collection and processing of samples}

Fourty-eight hours after the administration of paracetamol, blood samples were collected by cardiac puncture in plain dry tubes from all animals of six groups. The rats, from which blood samples were collected, were euthanized under light ether anesthesia, and their liver tissue was excised. Blood samples were centrifuged at 3,000 rpm for $10 \mathrm{~min}$ for the separation of sera. The serum samples obtained were transferred into eppendorf tubes and were preserved in a deep freezer at $-80^{\circ} \mathrm{C}$. The liver tissues were used for the analyses of oxidative stress parameters. Liver tissue samples were homogenized in chilled $50 \mathrm{mM}$ potassium phosphate buffer $(\mathrm{pH}$ 7.4). The homogenates were centrifuged at $10,000 \mathrm{rpm}$ for $20 \mathrm{~min}$ at $4^{\circ} \mathrm{C}$. The supernatants obtained were transferred into eppendorf tubes, and preserved at $-80^{\circ} \mathrm{C}$ in a deep freezer until used for analysis for various biochemical assays.

\section{Biochemical analysis}

Serum ALT, AST, ALP, activities were measured using Prietest clinical chemistry label kits and a Biochemical autoanalyser (Thomas, 1998; Henderson and Moss, 2001; Tielz, 1995) respectively. Protein levels in liver homogenates were measured as described by Lowry and Rosenbrough (1951). MDA analyses were performed in accordance with the method described by Ohkawa et al. (1979). GSH activity was measured as described by Ellman (1959). CAT activity was determined in accordance with the method described by Clairborne (1985), SOD activity was determined as described by Marklund (1985).

\section{Histopathological examinations}

Tissue samples were taken from the liver of the necropsied animals and fixed in $10 \%$ formalin neutral buffer solution. The trimmed tissues were first washed with tap water followed by dehydration through a graded alcohol series and then passed though xylol and paraffin series before finally blocked in paraffin. The paraffin blocks were cut into 5 to $6 \mathrm{~mm}$ sections using a microtome stained using hematoxylin and eosin and examined under a light microscope.

\section{Statistical analysis}

The results are presented as mean \pm standard error of mean (SEM). Significance of difference among the groups was determined by one-way ANOVA using Instat Graphpad and then differences among means were analyzed using Dunnett's test. Values of $\mathrm{P}<0.05$ were considered statistically significant.

\section{RESULTS}

\section{Biochemical findings}

A statistically significant difference was observed in serum ALT, AST and ALP levels in Group $2(P<0.01)$ as compared with Group 1 (Table 1). Also a statistically significant difference was observed in serum ALT, AST and ALP levels in Group 3, 5 and $6(\mathrm{P}<0.01)$ as compared with Group 2 (Table 1). No statistically significant difference was observed in serum ALT, AST and ALP levels in Group $4(\mathrm{P}<0.01)$ as compared with Group 2 (Table 1). Also, a statistically significant difference was observed in serum ALT, levels in Group $1 \quad(P<0.05)$, Group 2 $(P<0.01)$, decrease was observed as compared with Group 3 (Table 1). Group $4(\mathrm{P}<0.01)$ that is, with MESP no decrease was observed as compared with Group 3 (Table 1). A statistically significant difference was observed in serum AST, levels in Group $2(\mathrm{P}<0.01)$, Group $5(P<0.05)$ decrease was observed as compared with Group 3 (Table 1), Group $4(P<0.01)$ that is, with MESP no decrease was observed as compared with Group 3 (Table 1). A statistically significant difference was observed in serum ALP, levels in Group $2(P<0.01)$, Group $2(P<0.05)$ decrease was observed as compared with Group 3 (Table 1). Group $4(\mathrm{P}<0.01)$ that is, with MESP no decrease was observed as compared with Group 3 (Table 1).

A statistically significant difference was observed in liver MDA level and GSH, CAT, SOD (Table 2) in Groups $2(\mathrm{P}<0.01)$ as compared with Group 1 (Table 2). Also, a 
Table 2. Effect of Silymarin and S. paniculata extracts on Liver GSH, MDA levels, CAT and SOD activities.

\begin{tabular}{|c|c|c|c|c|}
\hline Group & $\begin{array}{c}\text { GSH } \\
(\mu \mathrm{mol} / \mathrm{g} \text { liver })\end{array}$ & $\begin{array}{c}\text { MDA } \\
\text { (nmol/g liver) }\end{array}$ & $\begin{array}{c}\text { Catalase } \\
\text { (Unit/mg protein) }\end{array}$ & $\begin{array}{c}\text { SOD } \\
\text { (Unit/mg Protein) }\end{array}$ \\
\hline NC & $298.00 \pm 7.92^{\dagger}$ & $2.28 \pm 0.41$ & $295.30 \pm 5.20$ & $21.59 \pm 1.07^{\dagger}$ \\
\hline PAR & $66.64 \pm 9.16^{\star \star \dagger \dagger}$ & $6.70 \pm 0.23^{* * \dagger \dagger}$ & $109.59 \pm 1.92^{\star \star \dagger \dagger}$ & $9.16 \pm 1.36^{* * \dagger \dagger}$ \\
\hline SMR & $210.06 \pm 6.76^{\star \star}$ & $2.77 \pm 0.23^{\star \star}$ & $253.82 \pm 5.66^{\star *}$ & $16.40 \pm 0.84^{\star \star}$ \\
\hline MESP & $82.10 \pm 7.64^{\#+\dagger}$ & $5.76 \pm 0.08^{\#+\dagger}$ & $120.78 \pm 1.82^{\#+\dagger}$ & $12.95 \pm 0.50^{\# \dagger}$ \\
\hline PEESP & $130.58 \pm 3.27^{* \star \dagger}$ & $3.27 \pm 0.16^{* \star \dagger}$ & $176.33 \pm 2.69^{\star \star \dagger}$ & $18.24 \pm 1.05^{\star *}$ \\
\hline EAESP & $159.26 \pm 5.73^{\star \star} \dagger$ & $2.91 \pm 0.23^{\star \star}$ & $217.15 \pm 3.51^{* *} \dagger$ & $16.94 \pm 0.94^{* *}$ \\
\hline
\end{tabular}

Values are expressed as mean \pm S.E.M for six rats in each group. Comparisons were made with toxic group (PAR) vs. all treated groups and control group, ** represents statistical significance at $\mathrm{P}<0.01$ and ${ }^{\#}$ indicates non significance. ${ }^{\dagger}$ represents comparison made with group (SMR) vs. all treated groups, ${ }^{\mathrm{t}}$ represents statistical significance at $\mathrm{P}<0.01$ and ${ }^{\dagger}$ represents statistical significance at $\mathrm{P}<0.05$. Catalase (CAT), nmol of $\mathrm{H}_{2} \mathrm{O}_{2}$ consumed per min per mg protein. Superoxide dismutase (SOD) amount of enzyme required to give $50 \%$ inhibition of pyrogallol auto oxidation, $U$ per mg protein.

statistically significant difference was observed in MDA level and GSH, CAT, SOD in Group 3, 5 and $6(\mathrm{P}<0.01)$ as compared with Group 2 (Table 2). No statistically significant difference was observed in MDA level and GSH, CAT, SOD in Group $4(\mathrm{P}<0.01)$ as compared with Group 2 (Table 2). Also, a statistically significant difference was observed in GSH levels in Group $1(P<0.05)$, Group $2(\mathrm{P}<0.01)$, Group $5(\mathrm{P}<0.05)$, Group $6(\mathrm{P}<0.05)$ decrease was observed as compared with Group 3 (Table 1). Group $4(\mathrm{P}<0.01)$ that is, with MESP, no increase in GSH levels was observed as compared with Group 3 (Table 2). A statistically significant difference was observed in MDA levels in Group $2(P<0.01)$ increased, Group $5(P<0.05)$ decreased MDA levels was observed as compared with Group 3 (Table 2). Group 4 $(P<0.01)$ that is, with MESP, no decrease was observed as compared with Group 3 (Table 2). Also, a statistically significant difference was observed in catalase levels in Group $2(\mathrm{P}<0.01)$ decreased, Group $5(\mathrm{P}<0.05)$ and 6 $(P<0.05)$ increased catalase activity was observed as compared with Group 3 (Table 2). Group $4(\mathrm{P}<0.01)$ that is, with MESP, no increase in catalase levels was observed as compared with Group 3 (Table 2). A statistically significant difference was observed in SOD levels in Group $1 \quad(\mathrm{P}<0.05)$ increase and Group 2 $(P<0.01)$ decreased $S O D$ levels was observed as compared with Group 3 (Table 2). Group $4(\mathrm{P}<0.05)$ with MESP, no increase was observed as compared with Group 3 (Table 2).

\section{Histopathological findings}

Group NC: Liver shows normal architecture. The central vein, portal tract and sinusoids appear normal (Figure 1A). Group PAR: Liver shows congested liver tissue with congested sinusoids and centrilobular necrosis with sparse infiltrate of lymphocytes and neutrophils (Figure 1B). Group SMR: Liver shows normal architecture with absence of fatty change and necrosis (Figure 1C). Group MESP: Liver shows congested liver tissue. At some places congested sinusoids with necrosis of perivenular hepatocytes with sparse infiltrate of lymphocytes were seen (Figure 1D). Group PEESP: Liver shows normal hepatic architecture with regeneration of hepatocytes and absence of fatty changes and necrosis (Figure 1E). Group EAESP: liver shows normal hepatic architecture with regeneration of hepatocytes and absence of fatty change and necrosis (Figure $1 \mathrm{~F}$ and Table 3).

\section{DISCUSSION}

Paracetamol is a common analgesic and antipyretic drug. Liver injury induced by paracetamol is the best characterized system of xenobiotic induced hepatotoxicity and is commonly used model for screening hepatoprotective drugs. Several studies have demonstrated the induction of hepatocellular damage or necrosis by paracetamol in higher doses in experimental animals and humans (Ayyavu and Shaheetha, 2009). For screening of hepatoprotective agents, paracetamol-induced hepatotoxicity has been used as a reliable method.

Paracetamol is metabolized primarily in the liver and eliminated by conjugation with sulfate and glucuronide, and then excreted by the kidney. Paracetamol hepatotoxicity has been attributed to the formation of toxic metabolites, when a part of paracetamol is activated by hepatic cytochrome P-450 to a highly reactive metabolite $\mathrm{N}$-acetyl-p-benzoquinoneimine (NAPQI) (Laura and Philip, 2003). N-acetyl-p-benzoquineimine can alkylate and oxidize intracellular GSH, which results in liver $\mathrm{GSH}$ depletion subsequently leads to increased lipid peroxidation by abstracting hydrogen from a polyunsaturated fatty 

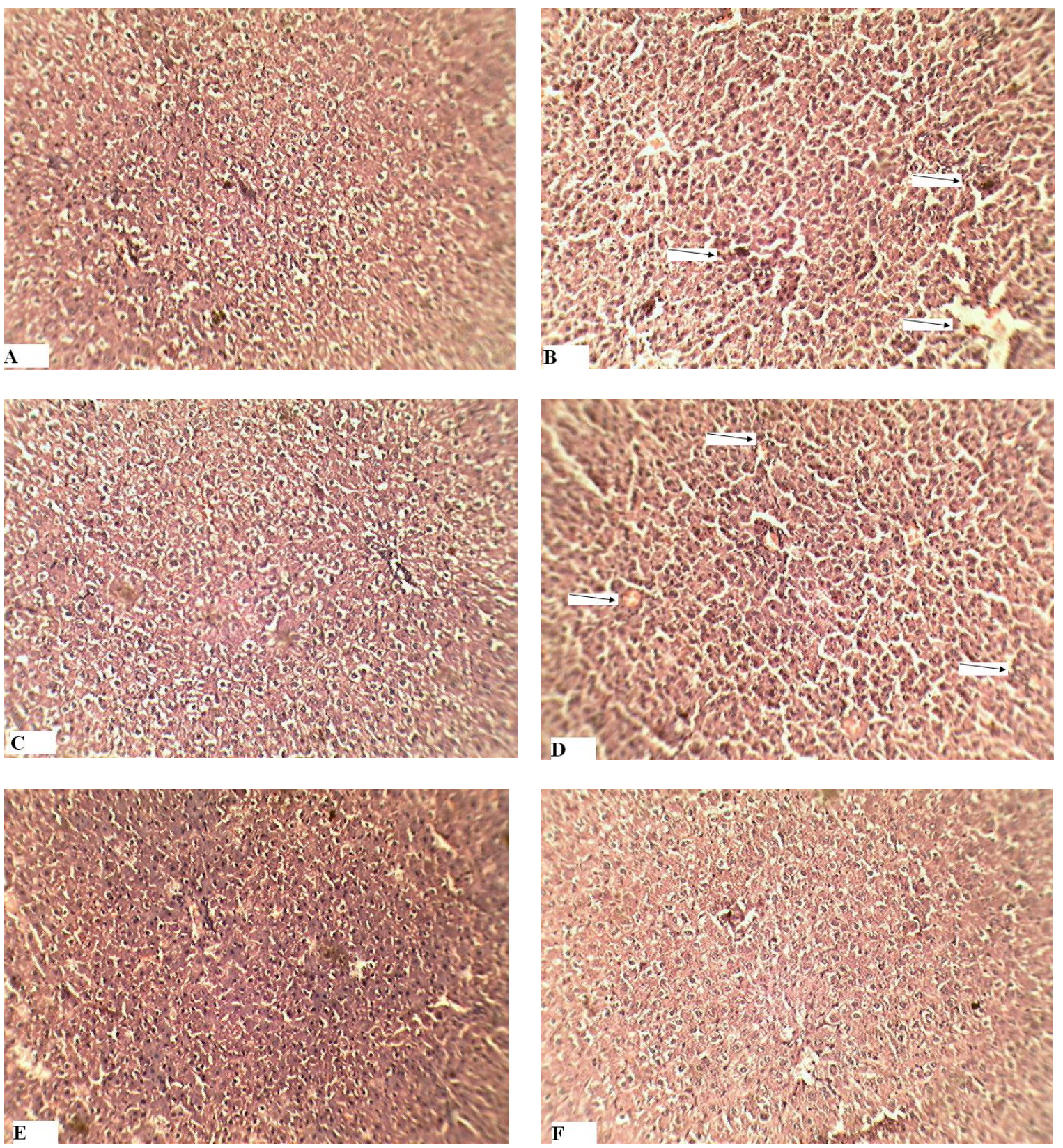

Figure 1. Effects of PAR, SMR, MESP, PEESP and EAESP on histopathological changes in liver of paracetamol induced hepatotoxicity in rats.

Rats were administered with silymarin, methanolic, petroleum ether, ethyl acetate extracts of S. paniculata for 10 days and paracetamol for 2 days. Livers were harvested, fixed in formalin and stained with hematoxylin and eosin for evaluation of pathological changes due to feeding a vehicle (A) paracetamol (B), Silymarin plus $3 \mathrm{gm} / \mathrm{kg} \mathrm{B.W}$. paracetamol (C) MESP plus 3gm/kg B.W. paracetamol (D) PEESP plus 3gm/ $\mathrm{kg} \mathrm{B.W.} \mathrm{paracetamol} \mathrm{(E)} \mathrm{EAESP} \mathrm{plus}$ $3 \mathrm{gm} / \mathrm{kg} \mathrm{B.W}$. paracetamol $(\mathrm{F})$. The photomicrographs show views of the liver sections, magnification $\times 40$.

fatty acid and ultimately, liver damage due to higher doses of paracetamol. Reactive metabolites can exert initial cell stress through a wide range of mechanisms including depletion of glutathione $(\mathrm{GSH})$ or binding to enzymes, lipids, nucleic acids and other cell structures (Simon and Patel, 2010).
AST is predominantly found in mitochondria of hepatocytes. ALT is more specific to liver, is one of the most sensitive tests employed in the diagnosis of hepatic diseases and thus is a better parameter for detecting liver injury. Serum ALP is also associated with liver cell damage. The ALT, AST and ALP activity are largely used 
Table 3. Effect of Silymarin and S. paniculata extracts on Liver histopathological changes.

\begin{tabular}{lccc}
\hline Group & Sinusoids & Centrilobular necrosis & Sparse infiltrate of lymphocytes and neutrophils \\
\hline NC & --- & --- & -- \\
PAR & +++ & +++ & +++ \\
SMR & --- & --- & -- \\
MESP & +++ & +++ & ++ \\
PEESP & --- & --- & -- \\
EAESP & --- & --- & --- \\
\hline
\end{tabular}

as most common biochemical markers to evaluate liver injury (Satyanarayan and Chakarapani, 2006). Administration of paracetamol caused a significant elevation of enzymes level such as AST, ALT and ALP, it has been attributed to damage of structural integrity of liver, because they are cytoplasmic in location and released into circulation after cellular damages indicating development of hepatotoxicity (Maheswari and Maryammal, 2008). The administrations of Petroleum ether extract $(500 \mathrm{mg} / \mathrm{kg})$ and Ethyl acetate extract $(500 \mathrm{mg} / \mathrm{kg})$ of $S$. paniculata flowers has significantly prevented the increased liver marker enzymes AST, ALT and ALP level, whereas methanol extract $(500 \mathrm{mg} / \mathrm{kg})$ of $S$. paniculata flowers failed to significantly reduce the increased serum marker enzymes AST, ALT and ALP level. This is in agreement with the commonly accepted view that serum levels of AST, ALT and ALP return to normal with the healing of hepatic parenchyma and the regeneration of hepatocytes (Mohamed et al., 2010). Among three different extracts of $S$. paniculata flowers, petroleum ether and ethyl acetate extracts exhibit excellent hepatoprotective properties as indicated by maximum prevention of increased serum biochemical parameters on paracetamol induced toxicity.

Catalase converts harmful hydrogen peroxide into water and oxygen and protects the tissues from highly reactive hydroxyl radicals. The reduction in the activity of this enzyme may results in number of deleterious effect due to accumulation of highly toxic metabolites and hydrogen peroxide on paracetamol administration, which has induced oxidative stress in the cells (Clairborne, 1985). Administration of petroleum ether and ethyl acetate extracts of $S$. paniculata flowers significantly increased the activity of catalase thereby protecting the liver from paracetamol intoxication, whereas methanol extracts of $S$. paniculata flowers did not significantly increase the activity of catalase in rats liver, thus it has not protected the liver from paracetamol intoxication.

SOD is an extremely effective antioxidant enzyme, and is responsible for catalytic dismutation of highly reactive and potentially toxic superoxide radicals to $\mathrm{H}_{2} \mathrm{O}_{2}$ (Marklund, 1985). The activities of SOD in the paracetamol group were significantly decreased when compared with the control group. The results strongly suggest that the significant decrease of hepatic SOD activities observed in rats treated with paracetamol may be largely due to increased free radical production and all the SOD enzymes content were utilized. In rats treated with petroleum ether and ethyl acetate extracts of $S$. paniculata flowers, the activity of this antioxidant enzyme were significantly higher than in the rats exposed to paracetamol alone. Whereas, methanol extracts of $S$. paniculata flowers did not significantly increase the activity of SOD in rats.

Reduced glutathione (GSH) is a substrate for glutathione related enzymes, and a regenerator for alphatocopherol, therefore it plays an important role in the antioxidant defense system. Reduced GSH removes free radical species such as hydrogen peroxide, superoxide radicals and maintains membrane protein thiols. The reduced GSH depletion in hepatic mitochondria is considered the most important mechanism in the paracetamol induced hepatotoxicity (Hui-Mei et al., 2008). Reduced GSH level was depleted in paracetamol treated group may be due to conjugation of reduced GSH with NAPQI to form mercapturic acid. In present study, administration of petroleum ether and ethyl acetate extracts of $S$. paniculata flowers has shown good ability to reduce oxidative stress by increasing the levels of reduced glutathione as compared to paracetamol intoxicated group.

The increase in MDA level in liver induced by paracetamol suggests enhanced lipid peroxidation leading to tissue damage and failure of antioxidant defense mechanism (Laura and Philip, 2003). A highly significant decrease in lipid peroxidation in liver tissue was observed in petroleum ether and ethyl acetate extracts of $S$. paniculata flowers treated groups. This indicates that petroleum ether and ethyl acetate extracts of flower possess antioxidant properties and has prevented the lipid peroxidation.

The studied plant extracts contain antioxidants and hepatoprotective activity through regulatory action on cellular permeability, stability and suppressing oxidative stress. Hence, it can be concluded that the possible mechanism of hepatoprotective activity of $S$. paniculata flowers may be due to the reduction of oxidative stress 
and its ability to reduce elevated levels of serum marker enzymes.

A number of scientific reports indicated that certain flavonoids, triterpenoids and steroids have protective effect on liver due to their antioxidant properties (Pradhan and Girish, 2006). In the present study, the phytochemical screening of the plant extracts was performed and it was found to contain flavonoids, tannins, phenolic compounds and Steroids. Therefore, it can be concluded that in S. paniculata flowers, flavonoids, sesquiterpene, steroids and bioactive phenolic compound might have prevented the liver injury induced by oxidative stress and the plant can play key role in hepatoprotective activity.

Further work on $S$. paniculata flowers for its phytochemical constituents and their active principle is necessary for the complete evaluation of its antioxidant and hepatoprotective activity.

\section{ACKNOWLEDGMENTS}

This study is supported by All India Council for Technical Education (AICTE), India. We thank Hon'ble Padamshree Mrs. Fatma Rafiq Zakaria, Chairman, Maulana Azad Educational Trust and Society for providing the research facility. We are thankful to Prof. Dileep Pokle, Department of Botany and Prof. Praveen Wakte, Department of Chemical Technology Dr. Babasaheb Ambedkar Marathwada University, Aurangabad for providing the assistance in authentification of plant and providing necessary help, respectively. We thank Mr. Shaikh Yusuf and Mr. Bhikan Shah for assisting in the experimental work.

\section{REFERENCES}

Ayyavu M, Shaheetha J (2009). Protective effect of Indian honey on acetaminophen induced oxidative stress and liver toxicity in rat. Biologia Section Zool. 64:1225-1231.

Chattopadhyay RR (2003). Possible mechanism of hepatoprotective activity of Azadirachta indica leaf extract: part II. J. Ethanopharmacol. 89:217-219.

Clairborne A (1985). Catalase activity. In: Greenwald RA (ed). Handbook of methods for oxygen radical research. CRC Press, Boca Raton, Florida. pp. 283-284.

Cohen SD, Khairalla HEA (1997). Selective protein arylation and acetaminophen-induced hepatotoxicity. Drug Metab. Rev. 29:59-77.

Dinda B, Guha S (1988). Chemical constituents of Spilanthes paniculata. J. Indian Chem. Soc. 65:525-526.
Ellman GL (1959). Tissue sulfhydryl groups. Arch. Biochem. Biophys. 82:70-77.

Henderson AR, Moss DW (2001). Enzymes. In: Burtis CA, Ashwood ER (eds). Tietz Fundamentals of Clinical Chemistry. WB Saunders, Philadelphia. p 352.

Hui-Mei L, Hsien-Chun T, Chau-Jong W (2008). Hepatoprotective effects of Solanum nigrum Linn extract against $\mathrm{CCl}_{4}$-iduced oxidative damage in rats. Chem. Biol. Interact. 171:283-293.

Laura PJ, Philip RM (2003). Acetaminophen-Induced Hepatotoxicity. Am. Soc. Pharmacol. Exp. Ther. 31:1449-1506.

Lowry OH, Rosenbrough NT (1951). Protein measurement with the Folins phenol reagent. J. Biol. Chem. 193:265-275.

Maheswari C, Maryammal R (2008). Hepatoprotective activity of Orthosiphon stamineus on liver damage caused by Paracetamol in rats. Jordan J. Biol. Sci. 1:105-108.

Marklund SL (1985). Pyrogallol autooxidation. In Handbook of methods for oxygen radical research, CRC Press Inc, Boca Raton, Florida, pp.243-247.

Mohamed STS, Madhusudhana CC, Ramkanth S (2010). Hepatoprotective Herbs; a Review. Int. J. Res. Pharm. Sci. 1:1-5.

Ohkawa H, Ohish N, Yagi K (1979). Assay lipid peroxides in animal tissues by thiobarbituric acid. Anal. Biochem. 95:351-358.

Pandey V, Agrawal V (2007). Strong larvicidal activity of three species of Spilanthes (Akarkara) against malaria (Anopheles stephensi Liston, Anopheles culicifacies, Species C) and filaria vector (Culex quinquefasciatus Say). J. Parasitol. Res.102:171-174.

Pradhan SC, Girish C (2006). Hepatoprotective herbal drug Silymarin from experimental pharmacology to clinical medicine. Indian J. Med. Res. 124:491-504.

Russmann S, Gerd A, Grattagliano I (2009). Current concepts of mechanisms in drug-induced hepatotoxicity. Curr. Med. Chem. 16:3041-3053.

Satyanarayan U, Chakarapani U (2006). Enzymes. In: Satyanarayan U (ed.). A textbook of Biochemistry. Interlinks, New Delhi. pp. 85-111.

Simon RP, Patel HV (2010). Hepatoprotective Activity of Some Plants extract against Paracetamol induced hepatotoxicity in rats. J. Herbal Med. Toxicol. 4:101-106.

The Wealth of India (2004). A dictionary of Indian raw material and industrial product, first supplement series. NISCAIR Press, New Delhi India p.146.

Thomas L (1998). Clinical laboratory diagnostics. In Use and Assessment of Clinical Laboratory Results, TH-Books, Verlagesellschaft mbH, Frankfurt p.652-656. ??? Not found in the body of work.

Tielz NW (1995). Clinical guide to laboratory tests, 3rd edn. WB Saunders Company, Philadelphia. pp 46, 76.

Vermeulen NPE, Bessems JGM, Vandestreat R (1991). Molecular aspects of paracetamol-induced hepatotoxicity and its mechanismbased prevention. Drug Metab. Rev. 24:367-407.

Wongsawatkul O (2008). Vasorelaxant and Antioxidant activities of Spilanthes acmella Murr. Int. J. Mol. Sci. 9:2724-2744. 